\title{
Incidence of perioperative medical complications and mortality among elderly patients undergoing surgery for spinal deformity: analysis of 3519 patients
}

\author{
Amit Jain, MD, ${ }^{1}$ Hamid Hassanzadeh, MD, ${ }^{2}$ Varun Puvanesarajah, MD, ${ }^{1}$ Eric O. Klineberg, MD, ${ }^{3}$ \\ Daniel M. Sciubba, MD, ${ }^{4}$ Michael P. Kelly, MD, ${ }^{5}$ D. Kojo Hamilton, MD, ${ }^{6}$ Virginie Lafage, PhD, ${ }^{7}$ \\ Aaron J. Buckland, MBBS, FRACS, ${ }^{8}$ Peter G. Passias, MD, ${ }^{8}$ Themistocles S. Protopsaltis, MD, ${ }^{8}$ \\ Renaud Lafage, MS, ${ }^{7}$ Justin S. Smith, MD, PhD, ${ }^{9}$ Christopher I. Shaffrey, MD, ${ }^{9}$ \\ Khaled M. Kebaish, MD, ${ }^{1}$ and the International Spine Study Group
}

\begin{abstract}
Departments of ${ }^{1}$ Orthopaedic Surgery and ${ }^{4}$ Neurosurgery, The Johns Hopkins University, Baltimore, Maryland; Departments of ${ }^{2}$ Orthopaedic Surgery and ${ }^{~}$ Neurosurgery, University of Virginia Health System, Charlottesville, Virginia; ${ }^{3} U C$ Davis School of Medicine, Sacramento, California; ${ }^{5}$ Department of Orthopaedic Surgery, Washington University, St. Louis, Missouri; ${ }^{6}$ Department of Neurological Surgery, University of Pittsburgh School of Medicine, Pittsburgh, Pennsylvania; ${ }^{7}$ Department of Orthopaedic Surgery, Hospital for Special Surgery, New York, New York; and ${ }^{8}$ Department of Orthopaedic Surgery, NYU Langone Medical Center, New York, New York
\end{abstract}

OBJECTIVE Using 2 complication-reporting methods, the authors investigated the incidence of major medical complications and mortality in elderly patients after surgery for adult spinal deformity (ASD) during a 2-year follow-up period.

METHODS The authors queried a multicenter, prospective, surgeon-maintained database (SMD) to identify patients 65 years or older who underwent surgical correction of ASD from 2008 through 2014 and had a minimum 2 years of followup $(n=153)$. They also queried a Centers for Medicare \& Medicaid Services claims database (MCD) for patients 65 years or older who underwent fusion of 8 or more vertebral levels from 2005 through $2012(n=3366)$. They calculated cumulative rates of the following complications during the first 6 weeks after surgery: cerebrovascular accident, congestive heart failure, deep venous thrombosis, myocardial infarction, pneumonia, and pulmonary embolism. Significance was set at $p<0.05$.

RESULTS During the perioperative period, rates of major medical complications were $5.9 \%$ for pneumonia, $4.1 \%$ for deep venous thrombosis, 3.2\% for pulmonary embolism, $2.1 \%$ for cerebrovascular accident, $1.8 \%$ for myocardial infarction, and $1.0 \%$ for congestive heart failure. Mortality rates were $0.9 \%$ at 6 weeks and $1.8 \%$ at 2 years. When comparing the SMD with the MCD, there were no significant differences in the perioperative rates of major medical complications except pneumonia. Furthermore, there were no significant intergroup differences in the mortality rates at 6 weeks or 2 years. The SMD provided greater detail with respect to deformity characteristics and surgical variables than the MCD.

CONCLUSIONS The incidence of most major medical complications in the elderly after surgery for ASD was similar between the SMD and the MCD and ranged from $1 \%$ for congestive heart failure to $5.9 \%$ for pneumonia. These complications data can be valuable for preoperative patient counseling and informed consent.

https://thejns.org/doi/abs/10.3171/2017.3.SPINE161011

KEY WORDS adult spinal deformity; elderly patients; major medical complications; Medicare claims database; surgeon-maintained database

ABBREVIATIONS ASD = adult spinal deformity; CHF = congestive heart failure; CVA = cerebrovascular accident; DVT = deep venous thrombosis, ICD-9-CM = International Classification of Diseases, 9th Revision, Clinical Modification; MCD = Centers for Medicare \& Medicaid Services claims database; MI = myocardial infarction; NIS = National (Nationwide) Inpatient Sample; NSQIP = National Surgical Quality Improvement Program; PE = pulmonary embolism; SMD = surgeon-maintained database; SRS = Scoliosis Research Society.

SUBMITTED August 26, 2016. ACCEPTED March 16, 2017.

INCLUDE WHEN CITING Published online August 18, 2017; DOI: 10.3171/2017.3.SPINE161011. 
$\mathrm{T}$ HE incidence of scoliosis in the elderly has been reported to be from $30 \%$ to $68 \% .^{25,27}$ Surgical treatment for adult spinal deformity (ASD) is associated with high complication rates..$^{16,17,35} \mathrm{~A}$ recent study found that approximately $27 \%$ of patients with ASD experience at least one medical complication perioperatively. ${ }^{33}$

High perioperative complication rates have been reported in elderly patients (aged 65 years or older) surgically treated for ASD and range from $37 \%$ to $71 \%$. 1,10,30,32 A large proportion of the morbidity in the elderly is caused by serious medical complications such as myocardial infarction (MI) and cerebrovascular accidents (CVAs), which become more prevalent with older age. Despite high complication rates, several studies have found that elderly patients may achieve equal or greater improvements in self-reported outcomes compared with younger patients (aged 64 years or younger) ${ }^{15,26,32}$ However, to our knowledge, no study has comprehensively assessed the rates of major medical complications among elderly patients surgically treated for ASD.

The aim of our study was to investigate the rates of major medical complications and mortality in elderly patients undergoing surgery for ASD by using 2 distinct complication-reporting methodologies: surgeon reporting by using a surgeon-maintained database (SMD), and administrative/billing abstraction using a Centers for Medicare \& Medicaid Services claims database (MCD). We hypothesized that the 2 methods would allow us to present a more comprehensive and accurate overview of complication rates.

\section{Methods}

Institutional review board approval was obtained from participating institutions.

\section{Study Population}

We defined "elderly" as aged 65 years or older and "perioperative period" as within 6 weeks after the index surgery.

\section{Complications}

The following major complications were queried in each database for the perioperative period: CVA, congestive heart failure (CHF), deep venous thrombosis (DVT), MI, pneumonia, and pulmonary embolism (PE).

\section{Surgeon-Maintained Database}

The SMD used in this study is a multicenter, prospective registry of academic institutions where surgery for ASD is performed. The criteria for enrollment in the database are as follows: major coronal curve magnitude of $20^{\circ}$ or more, sagittal vertical axis of $5 \mathrm{~cm}$ or more, pelvic tilt of $25^{\circ}$ or more, and/or thoracic kyphosis of $60^{\circ}$ or more. Patients are excluded if the spinal deformity is secondary to neuromuscular cause, infection, or malignancy.

The SMD was queried to identify elderly patients with ASD who were enrolled in the database from 2008 through 2014. Of the 1226 patients enrolled in the SMD, 737 were treated operatively. Of these, 450 were eligible for 2-year follow-up. Of these, 360 patients (80\%) had
TABLE 1. Characteristics of 3519 elderly patients who underwent surgery for ASD

\begin{tabular}{cccc}
\hline & \multicolumn{2}{c}{ No. of Patients (\%) } & \multirow{2}{*}{$\begin{array}{c}\text { C } \\
\text { Valuef }\end{array}$} \\
\cline { 2 - 3 } Characteristic & SMD* $^{*}$ & MCD & 0.631 \\
\hline $65-74$ & & & \\
\hline$\geq 75$ & $115(75)$ & $2422(72)$ & \\
\hline Female sex & $38(25)$ & $944(28)$ & \\
\hline No. of levels fused & $113(74)$ & $2606(77)$ & 0.622 \\
\hline $5-7$ & & & \\
\hline$\geq 8$ & $23(15)$ & 0.001 \\
\hline Comorbidities & $130(85)$ & $3366(100)$ & \\
\hline Cardiac disease & $28(18)$ & $798(24)$ & \\
\hline Diabetes mellitus & $18(12)$ & $592(18)$ & \\
\hline Hypertension & $77(50)$ & $2180(65)$ & \\
\hline Osteoporosis & $35(23)$ & $851(25)$ & \\
\hline Pulmonary disease & $10(7)$ & $805(24)$ & \\
\hline
\end{tabular}

* The multicenter SMD was queried from 2008 through 2014, resulting in 153 patients who met the inclusion criteria.

† The MCD was queried from 2005 through 2012, resulting in 3366 patients who met the inclusion criteria.

$\ddagger$ Calculated using chi-square tests.

2-year radiographic and clinical follow-up. Of the 360 patients, 153 (43\%) were 65 years or older and were included in the study (Table 1). Perioperative medical complications in the aforementioned categories were tabulated for these 153 patients. Patients who died within 6 weeks or 2 years after surgery were noted.

\section{Centers for Medicare \& Medicaid Services Claims Database}

The MCD data were accessed using the PearlDiver Patient Records Database (PearlDiver Technologies Inc.), which collates Medicare data from 2005 through 2012 in aggregate form. Access to the database was granted by PearlDiver Technologies for the purpose of academic research. The database can be queried using International Classification of Diseases, 9th Revision, Clinical Modification (ICD-9-CM) diagnostic and procedural codes. ${ }^{34}$

Using ICD-9-CM procedural codes 81.05, 81.07, and 81.64, we identified patients aged 65 years or older who had undergone posterior thoracolumbar or lumbosacral fusion of 8 or more vertebral levels. Furthermore, we selected for patients who had diagnostic codes associated with spinal deformity, including all variations of code 737.x. Patients with ASD in the setting of malignancy, infection, metastasis, or fractures were excluded. The final cohort from the MCD consisted of 3366 patients (Table 1). Major medical complications in the aforementioned categories were queried using corresponding ICD-9-CM codes. ${ }^{22-24}$ The mortality rates at 6 weeks and 2 years were tabulated.

\section{Statistical Analysis}

The data from the SMD and MCD were combined to 
TABLE 2. Major medical complications after surgery for ASD in patients aged $\geq 65$ years

\begin{tabular}{lccc}
\hline & \multicolumn{2}{c}{$\%$ of Patients } & $\begin{array}{c}p \\
\text { Value } \neq\end{array}$ \\
\cline { 2 - 3 } Complication & SMD $^{*}$ & MCD & \\
\hline CVA & 0 & 2.2 & 0.062 \\
\hline CHF & 0.7 & 1.0 & 0.664 \\
\hline DVT & 2.6 & 4.2 & 0.323 \\
\hline MI & 2.0 & 1.8 & 0.915 \\
\hline Pneumonia & 1.3 & 6.1 & 0.014 \\
\hline PE & 1.3 & 3.3 & 0.168 \\
\hline Death & & & \\
\hline 6 wks & 1.3 & 0.8 & 0.380 \\
\hline 2 yrs & 3.3 & 1.7 & 0.159 \\
\hline
\end{tabular}

* The multicenter SMD was queried from 2008 through 2014, resulting in 153 patients who met the inclusion criteria.

† The MCD was queried from 2005 through 2012, resulting in 3366 patients who met the inclusion criteria.

$\ddagger$ Significance was set at $p<0.05$.

estimate the overall rates of major medical complications. The complication and mortality rates were compared between the SMD and MCD cohorts using the z-test of proportions. Significance was set at $\mathrm{p}<0.05$.

\section{Results}

\section{Medical Complications and Mortality Rates}

During the perioperative period, the overall rates of major medical complications were $5.9 \%$ for pneumonia, $4.1 \%$ for DVT, 3.2\% for PE, $2.1 \%$ for CVA, $1.8 \%$ for MI, and $1.0 \%$ for CHF. Mortality rates were $0.9 \%$ at 6 weeks and $1.8 \%$ at 2 years. The cumulative rate of complications was $18.1 \%$.

\section{Surgeon-Maintained Database Versus Medicare Claims Database}

There were no significant differences in the perioperative rates derived from the SMD versus the MCD with respect to DVT $(2.6 \%$ vs $4.2 \%, \mathrm{p}=0.323)$, PE $(1.3 \%$ vs $3.3 \%, \mathrm{p}=0.168)$, CVA (0\% vs $2.2 \%, \mathrm{p}=0.062)$, MI $(2.0 \%$ vs $1.8 \%, \mathrm{p}=0.915)$, and $\mathrm{CHF}(0.7 \%$ vs $1.0 \%, \mathrm{p}=0.664)$ (Table 2). The rate of perioperative pneumonia was significantly lower in the SMD (1.3\% vs 6.1\%, p = 0.014). When comparing the SMD with the MCD, there were no significant differences in the mortality rates at 6 weeks $(1.3 \%$ vs $0.8 \%, \mathrm{p}=0.380)$ or 2 years $(3.3 \%$ vs $1.8 \%, \mathrm{p}=0.159)$.

\section{Discussion}

Surgical treatment of ASD is associated with major complications, which can result in deterioration of healthrelated quality-of-life outcomes. ${ }^{11}$ Elderly patients may be at higher risk of perioperative complications than their younger counterparts because of decreased physiological reserve.$^{36}$ The aim of the current study was to investigate the incidence of major medical complications and death among elderly patients after surgery for ASD using 2 inde- pendent complication-reporting methods. We hoped that using these 2 methods would allow us to present a more comprehensive and accurate overview of complication rates. Interestingly, we found that the rates of major medical complications after surgical correction of ASD in the elderly were similar between the 2 databases.

Studies in the spine literature increasingly use national databases such as the National (Nationwide) Inpatient Sample (NIS) (maintained by the Agency for Healthcare Research and Quality) and the National Surgical Quality Improvement Program (NSQIP) (maintained by the American College of Surgeons) to report complicationsrelated data. ${ }^{2,4-7,13}$ The NIS relies on hospitalization-based coding data, and the NSQIP relies on site-specific nurses who abstract data from patients' medical records. Because of errors in coding and adverse event reporting, recent studies have highlighted the inherent errors associated with data on complications derived from the NIS and the NSQIP and have recommended caution in their use.,12,14

Few studies in the spine literature ${ }^{18-20}$ have used the Medicare claims data, which are generally considered more comprehensive and accurate, ${ }^{18}$ because of the difficulties associated with accessing and querying them. In our study, we used the MCD to validate the results from our SMD and found similar complication and mortality rates derived from the 2 databases. Furthermore, the cumulative major medical complication rate of $18.1 \%$ in our study is similar to rates reported in previous studies focusing on patients undergoing ASD surgery. ${ }^{8,33,36}$ In a recent study, Soroceanu et al..$^{33}$ reported a major medical complication rate of $26 \%$ among 448 patients who had undergone surgery for ASD. Similarly, in reporting outcomes of a multicenter group from France, Charosky et al. ${ }^{8}$ reported a medical complication rate of $13.7 \%$ among 306 patients.

Although the aim of our study was not to compare the complication rate in elderly patients with that seen in their younger counterparts, some studies ${ }^{9,10}$ have shown that elderly patients are at significantly greater risk of complications after ASD surgery than younger patients. However, one study ${ }^{15}$ found no significant difference in the rate of postoperative complications between elderly and younger patients undergoing revision spinal deformity surgery. Sing et al. analyzed a national database of 29,237 patients who underwent ASD surgery and found that age was a significant risk factor for inpatient complications. ${ }^{29}$ In our experience, age is likely a major risk factor for complications after ASD surgery, and elderly patients require special preoperative counseling regarding the greater potential for complications.

Although we focused on elderly patients undergoing ASD surgery, we note that elderly patients undergoing spinal surgery for degenerative pathology are also at increased risk of complications. In a study of Medicare beneficiaries, Puvanesarajah et al. ${ }^{21}$ found complication rates of $12.5 \%$ among elderly patients undergoing 1 - to 2-level fusions and $20.5 \%$ among elderly patients undergoing 3- to 7-level fusions. Interestingly, they found that patients with deformities (those undergoing fusions of $\geq 8$ levels) had 10.8 times higher odds of dying during a 90 day follow-up period than did elderly patients undergoing 
1- to 2-level fusions for degenerative pathology. The differences could be attributable to greater surgical invasiveness of the spinal deformity surgery (more levels fused, use of osteotomies), as well as differences in preoperative frailty among patients with the different diagnoses.

In our study, the perioperative mortality rate was $0.9 \%$, which is similar to the $0.3 \%$ rate reported by Shaw et al. ${ }^{28}$ and the $0.35 \%$ rate reported by Smith et al., ${ }^{31}$ both of whom analyzed the Scoliosis Research Society (SRS) Morbidity and Mortality database. The SRS database relies on voluntary reporting by surgeons and is biased toward early perioperative outcomes. For instance, in the study by Smith et al., ${ }^{31} 79 \%$ of the 138 reported deaths occurred in the hospital. Using the SMD and the MCD in our study, we were able to estimate the 2-year risk of death as $1.8 \%$. However, it is important to note that the 2 -year mortality rate may not necessarily be attributable to the surgery but may reflect the mortality rate in the elderly population. To our knowledge, the baseline rate of 2-year mortality in elderly patients with ASD is not established.

Our study has several limitations. First, the MCD and SMD databases are fundamentally different. The MCD relies on administrative/billing data abstraction, whereas the SMD relies on surgeon reporting. Furthermore, in our analysis, the patients from the 2 databases were not matched a priori with respect to demographic characteristics, comorbidities, or surgical invasiveness. For example, the SMD group contains patients with $a \geq 5$-level fusion, whereas the MCD group contains patients with a $\geq 8$-level fusion. We felt that removing the $15 \%$ of patients in the SMD group with 5- to 7-level fusion would reduce the power to detect complications. We are unable to determine whether patients in the SMD and MCD had similarly complex surgical procedures because the MCD is limited with respect to surgical details and does not account for complex surgical elements such as 3-column osteotomies, which may have substantially influenced the surgical invasiveness and associated complication rates. In contrast, the SMD provided substantially greater detail with respect to patient radiographic and surgical characteristics compared with the MCD (Table 3).

Another limitation of our study is that we were unable to determine if patients in the MCD group were all patients with true spinal deformity. This is an inherent problem when using administrative databases, which do not contain radiographic data. Instead, administrative databases rely on billing codes as a surrogate for clinical diagnostic codes, which may not represent the same cohort of patients as the SMD. In comparison, all patients in the SMD group had known radiographic evidence of spinal deformity.

Furthermore, although the rates of most medical complications were similar between the MCD and SMD, the rate of pneumonia was significantly lower in the SMD. There could be several potential reasons for this. It is possible that patients who developed pneumonia were treated on an outpatient basis or were admitted to a medical service or to a different hospital and were thus missed by the SMD. Whereas the MCD is sensitive to such events because of its reliance on billing codes, the SMD relies on the information reported by patients to providers during follow-up clinical visits. It is also possible that the MCD
TABLE 3. Radiographic and surgical characteristics obtained from the SMD of patients aged $\geq 65$ years who underwent ASD surgery between 2008 and 2014

\begin{tabular}{cc}
\hline \multicolumn{1}{c}{ Characteristic } & Mean \pm SD \\
\hline Radiographic data & \\
\hline Preop & $27 \pm 18$ \\
\hline Coronal curve magnitude $\left(^{\circ}\right)$ & $0.37 \pm 4.8$ \\
\hline Coronal malalignment $(\mathrm{cm})$ & $28 \pm 10$ \\
\hline Pelvic tilt $\left(^{\circ}\right)$ & $10 \pm 6.6$ \\
\hline Sagittal malalignment $(\mathrm{cm})$ & $35 \pm 18$ \\
\hline T2-12 thoracic kyphosis $\left(^{\circ}\right)$ & $13 \pm 10$ \\
\hline 2-yr follow-up & $0.35 \pm 3.3$ \\
\hline Coronal curve magnitude $\left(^{\circ}\right)$ & $24 \pm 11$ \\
\hline Coronal malalignment $(\mathrm{cm})$ & $1.1 \pm 5.9$ \\
\hline Pelvic tilt $\left({ }^{\circ}\right)$ & $54 \pm 17$ \\
\hline Sagittal malalignment $(\mathrm{cm})$ & $1.96 \pm 1.88$ \\
\hline T2-12 thoracic kyphosis $\left(^{\circ}\right)$ & $11 \pm 4$ \\
\hline Surgical data & $390 \pm 129$ \\
\hline Estimated blood loss $(\mathrm{L})$ & 24 \\
\hline No. of levels fused & \\
\hline Op time (mins) & \\
\hline Patients w/ 3-column osteotomies $(\%)$ &
\end{tabular}

The multicenter SMD was queried from 2008 through 2014, resulting in 153 patients who met the inclusion criteria. In contrast, none of these characteristics were reported in the Centers for Medicare \& Medicaid Services claims database.

overestimates rates of events such as pneumonia because of carrying forward of prior diagnoses. The temporal relationship between an intervention and a medical event such as pneumonia can be obscured when performing crosssectional analysis using billings codes. In our study, we used an alpha level of 0.05. Had we used a Bonferroni correction to adjust our alpha to 0.007 to minimize the likelihood of Type 1 error, the difference in perioperative rates of pneumonia between the SMD and MCD groups would not have been found to be statistically significant. Despite these limitations, our study aimed to establish the rates of major medical complications among elderly patients treated with surgery for spinal deformity, yielding similar rates despite 2 contrasting complication-reporting strategies.

\section{Conclusions}

Elderly patients with ASD are at risk for major medical complications, including pneumonia, thromboembolic events, CVA, MI, and CHF. The mortality rates among elderly patients after spinal fusion surgery for ASD are approximately $0.9 \%$ at 6 weeks and $1.8 \%$ at 2 years. A multicenter SMD allowed for accurate capture of major medical complication rates and provided substantially greater detail with respect to patient radiographic and surgical characteristics compared with the MCD. The complications data reported in our study can be valuable for preoperative patient counseling and informed consent. 


\section{References}

1. Acosta FL Jr, McClendon J Jr, O'Shaughnessy BA, Koller H, Neal CJ, Meier O, et al: Morbidity and mortality after spinal deformity surgery in patients 75 years and older: complications and predictive factors. J Neurosurg Spine 15:667-674, 2011

2. Basques BA, Diaz-Collado PJ, Geddes BJ, Samuel AM, Lukasiewicz AM, Webb ML, et al: Primary and revision posterior lumbar fusion have similar short-term complication rates. Spine (Phila Pa 1976) 41:E101-E106, 2016

3. Bohl DD, Russo GS, Basques BA, Golinvaux NS, Fu MC, Long WD III, et al: Variations in data collection methods between national databases affect study results: a comparison of the nationwide inpatient sample and national surgical quality improvement program databases for lumbar spine fusion procedures. J Bone Joint Surg Am 96:e193, 2014

4. Bohl DD, Shen MR, Mayo BC, Massel DH, Long WW, Modi $\mathrm{KD}$, et al: Malnutrition predicts infectious and wound complications following posterior lumbar spinal fusion. Spine (Phila Pa 1976) 41:1693-1699, 2016

5. Bohl DD, Webb ML, Lukasiewicz AM, Samuel AM, Basques BA, Ahn J, et al: Timing of complications after spinal fusion surgery. Spine (Phila Pa 1976) 40:1527-1535, 2015

6. Buerba RA, Fu MC, Grauer JN: Anterior and posterior cervical fusion in patients with high body mass index are not associated with greater complications. Spine J 14:1643-1653, 2014

7. Buerba RA, Giles E, Webb ML, Fu MC, Gvozdyev B, Grauer $\mathrm{JN}$ : Increased risk of complications after anterior cervical discectomy and fusion in the elderly: an analysis of 6253 patients in the American College of Surgeons National Surgical Quality Improvement Program database. Spine (Phila Pa 1976) 39:2062-2069, 2014

8. Charosky S, Guigui P, Blamoutier A, Roussouly P, Chopin D: Complications and risk factors of primary adult scoliosis surgery: a multicenter study of 306 patients. Spine (Phila Pa 1976) 37:693-700, 2012

9. Cho SK, Bridwell KH, Lenke LG, Yi JS, Pahys JM, Zebala LP, et al: Major complications in revision adult deformity surgery: risk factors and clinical outcomes with 2- to 7-year follow-up. Spine (Phila Pa 1976) 37:489-500, 2012

10. Daubs MD, Lenke LG, Cheh G, Stobbs G, Bridwell KH: Adult spinal deformity surgery: complications and outcomes in patients over age 60. Spine (Phila Pa 1976) 32:22382244, 2007

11. Glassman SD, Hamill CL, Bridwell KH, Schwab FJ, Dimar JR, Lowe TG: The impact of perioperative complications on clinical outcome in adult deformity surgery. Spine (Phila Pa 1976) 32:2764-2770, 2007

12. Golinvaux NS, Bohl DD, Basques BA, Fu MC, Gardner EC, Grauer JN: Limitations of administrative databases in spine research: a study in obesity. Spine J 14:2923-2928, 2014

13. Golinvaux NS, Varthi AG, Bohl DD, Basques BA, Grauer $\mathrm{JN}$ : Complication rates following elective lumbar fusion in patients with diabetes: insulin dependence makes the difference. Spine (Phila Pa 1976) 39:1809-1816, 2014

14. Gologorsky Y, Knightly JJ, Chi JH, Groff MW: The Nationwide Inpatient Sample database does not accurately reflect surgical indications for fusion. J Neurosurg Spine 21:984993, 2014

15. Hassanzadeh H, Jain A, El Dafrawy MH, Ain MC, Skolasky RL, Kebaish KM: Clinical results and functional outcomes in adult patients after revision surgery for spinal deformity correction: patients younger than 65 years versus 65 years and older. Spine Deform 1:371-376, 2013

16. Hassanzadeh H, Jain A, El Dafrawy MH, Mesfin A, Neubauer PR, Skolasky RL, et al: Clinical results and functional outcomes of primary and revision spinal deformity surgery in adults. J Bone Joint Surg Am 95:1413-1419, 2013

17. Lapp MA, Bridwell KH, Lenke LG, Daniel Riew K, Linville DA, Eck KR, et al: Long-term complications in adult spinal deformity patients having combined surgery a comparison of primary to revision patients. Spine (Phila Pa 1976) 26:973983, 2001

18. Martin BI, Lurie JD, Tosteson AN, Deyo RA, Tosteson TD, Weinstein JN, et al: Indications for spine surgery: validation of an administrative coding algorithm to classify degenerative diagnoses. Spine (Phila Pa 1976) 39:769-779, 2014

19. Modhia U, Takemoto S, Braid-Forbes MJ, Weber M, Berven $\mathrm{SH}$ : Readmission rates after decompression surgery in patients with lumbar spinal stenosis among Medicare beneficiaries. Spine (Phila Pa 1976) 38:591-596, 2013

20. Ong KL, Auerbach JD, Lau E, Schmier J, Ochoa JA: Perioperative outcomes, complications, and costs associated with lumbar spinal fusion in older patients with spinal stenosis and spondylolisthesis. Neurosurg Focus 36(6):E5, 2014

21. Puvanesarajah V, Cancienne JM, Werner BC, Jain A, Singla A, Shimer AL, et al: Perioperative complications associated with posterolateral spine fusions: a study of elderly Medicare beneficiaries. Spine (Phila Pa 1976) [epub ahead of print], 2017

22. Puvanesarajah V, Jain A, Cancienne JM, Shimer AL, Singla A, Shen F, et al: Complication and reoperation rates following surgical management of cervical spondylotic myelopathy in Medicare beneficiaries. Spine (Phila Pa 1976) 42:1-7, 2017

23. Puvanesarajah V, Jain A, Hess DE, Shimer AL, Shen FH, Hassanzadeh H: Complications and mortality after lumbar spinal fusion in elderly patients with late stage renal disease. Spine (Phila Pa 1976) 41:E1298-E1302, 2016

24. Puvanesarajah V, Jain A, Shimer AL, Shen FH, Hassanzadeh $\mathrm{H}$ : The effect of coagulopathies on perioperative complications and clinical outcomes in patients treated with posterior lumbar fusions. Spine (Phila Pa 1976) 41:E1063-E1068, 2016

25. Robin GC, Span Y, Steinberg R, Makin M, Menczel J: Scoliosis in the elderly: a follow-up study. Spine (Phila Pa 1976) 7:355-359, 1982

26. Scheer JK, Lafage V, Smith JS, Deviren V, Hostin R, McCarthy IM, et al: Impact of age on the likelihood of reaching a minimum clinically important difference in 374 three-column spinal osteotomies: clinical article. J Neurosurg Spine 20:306-312, 2014

27. Schwab F, Dubey A, Gamez L, El Fegoun AB, Hwang K, Pagala M, et al: Adult scoliosis: prevalence, SF-36, and nutritional parameters in an elderly volunteer population. Spine (Phila Pa 1976) 30:1082-1085, 2005

28. Shaw R, Skovrlj B, Cho SK: Association between age and complications in adult scoliosis surgery: an analysis of the Scoliosis Research Society Morbidity and Mortality Database. Spine (Phila Pa 1976) 41:508-514, 2016

29. Sing DC, Berven SH, Burch S, Metz LN: Increase in spinal deformity surgery in patients age 60 and older is not associated with increased complications. Spine (Phila Pa 1976) 17:627-635, 2017

30. Skolnick A: New osteoporosis therapies appear closer. JAMA 263:1753, 1990

31. Smith JS, Saulle D, Chen CJ, Lenke LG, Polly DW Jr, Kasliwal MK, et al: Rates and causes of mortality associated with spine surgery based on 108,419 procedures: a review of the Scoliosis Research Society Morbidity and Mortality Database. Spine (Phila Pa 1976) 37:1975-1982, 2012

32. Smith JS, Shaffrey CI, Glassman SD, Berven SH, Schwab FJ, Hamill CL, et al: Risk-benefit assessment of surgery for adult scoliosis: an analysis based on patient age. Spine (Phila Pa 1976) 36:817-824, 2011 
33. Soroceanu A, Burton DC, Oren JH, Smith JS, Hostin R, Shaffrey CI, et al: Medical complications after adult spinal deformity surgery: incidence, risk factors, and clinical impact. Spine (Phila Pa 1976) 41:1718-1723, 2016

34. United States Health Care Administration: International Classification of Diseases, 9th Revision, Clinical Modification: Med-Index ICD-9-CM, ed 4. Salt Lake City: MedIndex Publications, 1993

35. Weistroffer JK, Perra JH, Lonstein JE, Schwender JD, Garvey TA, Transfeldt EE, et al: Complications in long fusions to the sacrum for adult scoliosis: minimum five-year analysis of fifty patients. Spine (Phila Pa 1976) 33:1478-1483, 2008

36. Worley N, Marascalchi B, Jalai CM, Yang S, Diebo B, Vira S, et al: Predictors of inpatient morbidity and mortality in adult spinal deformity surgery. Eur Spine J 25:819-827, 2016

\section{Disclosures}

The International Spine Study Group receives funding from DePuy Synthes for administrative support and data collection. The authors report the following. Dr. Hassanzadeh: support of non-study-related clinical or research effort from Pfizer and from Orthofix; consultant for NuVasive. Dr. Kelly: support of nonstudy-related clinical or research effort from AOSpine, PCORI, Barnes Jewish Foundation, OREF, and CSRS. Dr. Klineberg: consultant for DePuy Synthes and Stryker; honoraria from K2M; and honoraria and fellowship grant from AOSpine. Dr. V. Lafage: stock ownership in Nemaris Inc.; consultant for NuVasive; support of non-study-related clinical or research effort from DePuy Spine, K2M, Stryker, NuVasive (paid through ISSGF), and SRS and received teaching/educational support from DePuy Spine, MSD, NuVasive, and K2M. Dr. Passias: consultant for Medicrea and support for educational course work. Dr. Protopsaltis: consultant for Medicrea, Globus, NuVasive, and Innovasis; support of non-study-related clinical or research effort from Cervical Spine Research Society and from Zimmer Biomet. Dr. Sciubba: consultant for Medtronic, DePuy-Synthes, and Globus; ownership in Stryker. Dr. Shaffrey: consultant for Medtronic, NuVasive, Zimmer-Biomet, and K2M; direct stock ownership in NuVasive; patent holder in Medtronic, NuVasive, and Zimmer-Biomet; and support of non-study-related clinical or research effort from DePuy-Synthes. Dr. Smith: consultant for Zimmer-Biomet, NuVasive, and Cerapedics; clinical or research support (includes equipment or material) from DePuy-Synthes/ISSG; support of non-study-related clinical or research effort from DePuy-Synthes/ ISSG; honorarium for course work from K2M; and fellowship funding from NREF and AOSpine.

\section{Author Contributions}

Conception and design: all authors. Acquisition of data: Jain. Analysis and interpretation of data: Jain, Hassanzadeh, Klineberg. Drafting the article: Kebaish, Jain, Hassanzadeh, Puvanesarajah, Klineberg, Sciubba, Kelly, Hamilton, V Lafage, Buckland, Protopsaltis, R Lafage, Smith, Shaffrey. Critically revising the article: all authors. Reviewed submitted version of manuscript: Kebaish, Jain, Hassanzadeh, Puvanesarajah, Klineberg, Sciubba, Kelly, Hamilton, V Lafage, Passias, Protopsaltis, R Lafage, Smith, Shaffrey. Approved the final version of the manuscript on behalf of all authors: Kebaish. Statistical analysis: Passias. Study supervision: Kebaish.

\section{Correspondence}

Khaled M. Kebaish, Department of Orthopaedic Surgery, The Johns Hopkins University, 601 North Caroline St., Baltimore, MD 21287. email: kkebais@jhmi.edu. 